Vol 10, Issue 10, 2017

\title{
FORMULATION AND EVALUATION IN VITRO A MATRIX TYPE OF KETOTIFEN FUMARATE TRANSDERMAL PATCHES FOR ALLERGIC DISEASES
}

\author{
LAMA HAMDAN*, JAMILA HUSIAN \\ Department of Pharmaceutical Technology, Faculty of Pharmacy, Damascus University, Damascus, Syria. \\ Email: lama.hamdan78@gmail.com
}

Received: 20 May 2017, Revised and Accepted: 04 July 2017

\section{ABSTRACT}

Objective: Transdermal patches of Ketotifen fumarate (KT) were developed for prolonged effect of the drug, and to protect the patient from allergic symptoms associated with asthma and other allergic diseases.

Methods: Matrix type patches were prepared by solvent casting technique using different types of polymers: Hydroxy propyl methyl cellulose (HPMC K15M) and ethyl cellulose to formed the matrix of the patch in different ratios, emulsifying agents were added as a penetration enhancers (Span 60, Tween 60, Cremophor EL) in a ratio $0.025 \% \mathrm{w} / \mathrm{v}$ to the matrix, $10 \% \mathrm{v} / \mathrm{v}$ of glycerin was added as plasticizer to $10 \mathrm{ml}$ of chloroform:methanol (1:1). The drug matrix film was casted on a polyvinyl alcohol backing membrane. All patches were evaluated for physical proprieties, thickness uniformity, folding endurance, moisture uptake, moisture content, drug content, uniformity of weight, content uniformity, in vitro drug release, and kinetic models. Differential scanning calorimetry was used to characterize physical mixtures of KT and the different used excipients.

Results: The results showed that the prepared patches had acceptable physical properties. The drug substance was released well. Adding the penetration enhancers delayed the release of the drug from the matrix in all the prepared formulas, formula A2 that having no enhancer, showed maximum amounts of drugs release $(90.06 \pm 0.9) \%$ for 24 hrs. However, adding penetration enhancers decreased the amount of the drug release, formula B2 having Tween 60 as a penetration enhancer, showed the maximum release of the drug (87.78 \pm 0.88$) \%$, and formula B3 having Cremophor EL showed the minimum release of the drug $(79.13 \pm 1.58)$ at the end of 24 hrs dissolution study. The release of the drug from all formulations was followed by Korsmeyer-Peppas pattern with $n>0.45$ indicating that drug release from matrix was mainly happened by swallowed and diffusion (nonFickian pattern).

Conclusion: Optimized formula A2 containing the maximum amounts of HPMC K15M showed a controlled release of the drug over 12 hrs, and it identified as a successful formulation for this study.

Keywords: Transdermal matrix patch, Ketotifen fumarate, Hydroxypropyl methylcellulose K15M, Ethyl cellulose, Span 60, Tween 60, Cremophor EL, Solvent casting technique.

(C) 2017 The Authors. Published by Innovare Academic Sciences Pvt Ltd. This is an open access article under the CC BY license (http://creativecommons. org/licenses/by/4. 0/) DOI: http://dx.doi.org/10.22159/ajpcr.2017.v10i10.20123

\section{INTRODUCTION}

Ketotifen fumarate (KT) is an antiallergic drug. It is widely used for the treatment of many allergic diseases such as asthma, urticaria, allergic rhinitis, and allergic conjunctivitis. The pharmacodynamics properties of Ketotifen are many because it is an inhibitor of the release and activity of mast cell and basophil mediators, including histamine and leukotrienes. Thus, it inhibits the bronchial, ocular, nasal, and dermal responses due to exposure to allergens [1]

KT is administered orally in a dose $1 \mathrm{~m}$ twice a day, but bioavailability is reported about $50 \%$ due to the hepatic first pass metabolism [2], by CYP3A4 and oxidation. Most of the Ketotifen is eliminated and excretion mainly by kidney to an inactive metabolite with a small amount of unchanged drug [3].

Transdermal therapeutic system was specifically designed to obtain systemic blood levels and have been used in the United States since 1950s. The advantages are: Avoiding the chemically hostile gastrointestinal environment, providing adequate absorption of certain drugs that increase patient compliance, also avoiding the first pass effect and it useful for the effective use of drugs with short biological half-lives, and also provides controlled plasma levels of the drug.

In transdermal delivery, the drug enters the systemic circulation without first passing into the hepatic portal system and traversing the liver. In addition, it gives sustained blood levels and avoids the "saw tooth" pattern seen with modes of administration [4]. There are many types of patches which are [5]:

1. Drug-in-adhesive patches: It is the simplest form and most common patch design. These patches are formed by dissolving or dispersing drug within an adhesive which is then coated onto a backing layer before a release liner is applied.

2. Matrix patches: In matrix type transdermal patches [6], the drug is dispersed homogeneously in a hydrophilic or lipophilic polymer matrix. Drug containing polymer disk then is fixed onto an occlusive base plate in a compartment fabricated form of a drug-impermeable backing layer. Layers of the patched are shown in Fig. 1.

3. Rate-limiting membrane-type patches: This type contains the drug in a reservoir but with release controlled through a semipermeable membrane. The reservoir may be liquid or more usually a gel and can be used for prolonged delivery.

To deliver the drug through the skin, it should have a greater physicochemical attraction to the skin than to the vehicle, and the solubility of the drug in both lipid and water, which is thought to be essential for effective percutaneous absorption, so that ideally enables $\log$ partition coefficient $(\log \mathrm{p})$ should be in the range 1-4 to deliver the skin layers.

In addition, drugs with a molecular weight of 100-800 Da can permeate skin. The ideal molecular weight of a drug for transdermal drug delivery 
is believed to be 400 or less. In general, drugs penetrate the skin better in their unionized form [7].

The aim of this study was to develop different transdermal matrix patches with varied hydroxypropyl methylcellulose (HPMC K15M) and ethyl cellulose (EC), containing the drug KT. The purpose was to provide the delivery of drug at a controlled rate across intact skin to achieve a therapeutically effective drug level for a longer period of time from transdermal patches.

\section{MATERIALS AND METHODS}

\section{Materials}

KT was purchased from Zhejiang Huahai Pharmaceutical Co., Ltd. China, HPMC K15M was purchased from Shreeji Ltd, (Mumbai, India), EC was purchased from HiMedia Ltd, (Mumbai, India), Glycerin was obtained from Sigma-Aldrich, UK, Span 60 and Tween 60 were obtained from (E. Merck, Germany). Menthol was purchased from sun pharmaceutical, India, Chloroform was received from BDH Chemical Ltd, England, methanol was received from (E. Merck, Germany), and Cremophor EL was received as a gift sample from Dar Al Dawa, Jordan.

\section{Formulation of transdermal patches}

Backing membrane of the patch was prepared using $4 \% \mathrm{w} / \mathrm{v}$ polyvinyl alcohol (PVA), by adding $4 \mathrm{~g}$ of PVA to $100 \mathrm{ml}$ distilled water with stirring on a magnetic stirrer at $80^{\circ} \mathrm{C}$. After cooling, PVA solution was deaerated for 2 minutes by Sonicator. $1 \mathrm{ml}$ of the solution was poured in circular aluminum foil cups placed in circular mineral mold with diameter $5 \mathrm{~cm}$ and put aside to dry at $25^{\circ} \mathrm{C}$ for $24 \mathrm{hrs}$ [8].

Transdermal patches were prepared by solvent casting technique. Polymeric solution obtained by adding the polymers at ratio $(0.5 \% \mathrm{w} / \mathrm{v})$ in $10 \mathrm{ml}$ methanol:chloroform (1:1) as a solvent, glycerin $(10 \% \mathrm{v} / \mathrm{v})$ and different penetration enhancers (Span 60, Tween 60, Cremophor EL) $(0.025 \% \mathrm{w} / \mathrm{v})$ and the drug were added (Table 1$)$.

All ingredients were mixed with ultrasound for $1 \mathrm{hr}$ to obtain a homogenous solution [9]. Finally, $10 \mathrm{ml}$ from polymeric solution with the drug was poured on the PVA that prepared previously and covered with parafilm to avoid fast evaporation solvent for $24 \mathrm{hrs}$.

\section{Drug excipient interaction study [10]}

About $5 \mathrm{mg}$ of the sample was achieved by (Mettler Toledo-OH, USA) differential scanning calorimetry (DSC). Temperature was rising from 30 to $350^{\circ} \mathrm{C} /$ minutes. DSC of pure drug, excipients, and excipients with drug was taken.

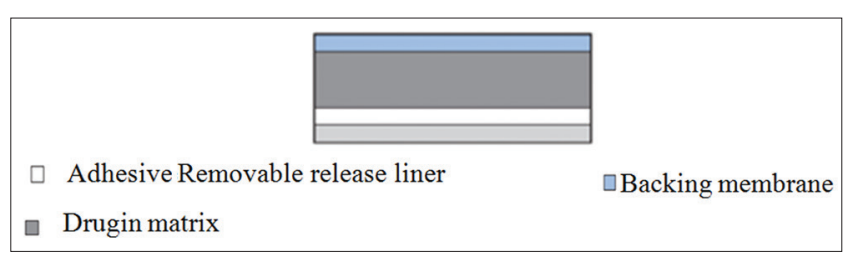

Fig. 1: Layers of transdermal patch

\section{Evaluation of transdermal patches}

\section{Physical appearance}

The patches were observed visually for clarity, smoothness, and completeness.

\section{Thickness uniformity [11]}

The thickness of prepared patches was measured by micrometer screw gauge in 3 different points, and the average reported.

\section{Folding endurance [12]}

Folding endurance was measured by repeatedly folding the patch at the same place until it broke. The number of times the patch could be folded at the same place without breaking represented the folding endurance value.

\section{Percentage of moisture uptake [13]}

The accurate weight of 3 patches was kept in desiccators containing saturated solution of potassium chloride in the oven at $25^{\circ} \mathrm{C}$ to maintain $80-90 \%$ relative humidity. The patches were weighted again after 24 , 48, and $72 \mathrm{hrs}$ and the percentage moisture uptake was calculated using the formula below:

$$
\mathrm{M} \%=\frac{\text { Final weight }- \text { Initial weight }}{\text { Initial weight }} \times 100
$$

\section{Percentage of moisture content [14]}

The accurate weight of 3 patches was kept in desiccators containing fused calcium chloride in the oven at $25^{\circ} \mathrm{C}$ to maintain $80-90 \%$ relative humidity. The patches were weighted again after 24,48 , and $72 \mathrm{hrs}$ and the percentage moisture content was calculated from the formula below:

$\mathrm{M} \%=\frac{\text { Final weight }- \text { Initial weight }}{\text { Final weight }} \times 100$

\section{Content uniformity [15]}

Content uniformity was determined by a procedure reported by European Pharmacopeia ( $7^{\text {th }}$ ed, 2011). 10 patches were taken, and each one was put in $100 \mathrm{ml}$ distilled water at the volumetric flask, and stirred with ultrasound to extract the drug. The content was filtered through a Whatman filter paper, and filtrate was examined for the drug content against the reference solution containing placebo patches with the ultraviolet spectrophotometer at $303 \mathrm{~nm}$ [16] and average was calculated.

\section{In vitro release study [8]}

In vitro release study was conducted in Franz Cell with the volume of receptor compartment $30 \mathrm{ml}$ and cellulose nitrate with diameter $45 \mu \mathrm{m}$ was used.

The receptor medium (distilled water) was filled in the receptor compartment and temperature set at $32 \pm 1^{\circ}$ with stirring at a speed of $500 \mathrm{rpm}$. The patch was placed over the membrane, and glass disk of donor compartment was placed over receptor compartment, and both compartments were fixed together. A sample of $5 \mathrm{ml}$ was withdrawn at $0.25,0.5,1,2,3,4,5,6,7,8,9,10,11,12$, and $24 \mathrm{hrs}$ from the sampling port with a long needle syringe and replaced

Table 1: Formulation of transdermal patches

\begin{tabular}{|c|c|c|c|c|c|c|}
\hline Ingredient & FA1 & FA2 & FA3 & FB1 & FB2 & FB3 \\
\hline$* \mathrm{KT}(\mathrm{mg})$ & 2 & 2 & 2 & 2 & 2 & 2 \\
\hline *HPMC K15M (mg) & 25 & 35 & 15 & 35 & 35 & 35 \\
\hline *EC (mg) & 25 & 15 & 35 & 15 & 15 & 15 \\
\hline Glycerin (ml) & $10 \% \mathrm{v} / \mathrm{v}$ & $10 \% \mathrm{v} / \mathrm{v}$ & $10 \% \mathrm{v} / \mathrm{v}$ & $10 \% \mathrm{v} / \mathrm{v}$ & $10 \% \mathrm{v} / \mathrm{v}$ & $10 \% \mathrm{v} / \mathrm{v}$ \\
\hline Span 60 & - & - & - & $0.025 \% \mathrm{w} / \mathrm{v}$ & & \\
\hline Tween 60 & - & - & - & - & $0.025 \% \mathrm{w} / \mathrm{v}$ & \\
\hline Cremophor EL & - & - & - & - & - & $0.025 \% \mathrm{w} / \mathrm{v}$ \\
\hline
\end{tabular}

${ }^{*}$ KT: Ketotifen fumarate, ${ }^{*}$ HPMC: Hydroxypropyl methylcellulose, ${ }^{*}$ EC: Ethyl cellulose 
by an equal volume at each sampling time. Dissolution medium was used to take the blank reading, and samples were analyzed on spectrophotometry at a wave length of $303 \mathrm{~nm}$ to measure the released amounts of the drug.

\section{Statistical analyses}

All the results were expressed as mean values \pm standard deviation. The difference between percentages of Ketotifen released at specified time intervals, from the different formulations, were statistically evaluated using Friedman test. For results interpretation, $p$ value was significant when $\mathrm{p}<0.05$

\section{Kinetic analysis of release data}

To describe the release models, in vitro release data from patches were analyzed according to a zero-order kinetic model, a firstorder release model, a diffusion controlled model (Higuchi model), a Hixson-Crowell release model, and a Korsmeyer-Peppas model. The model that consistently produced the highest correlation among the prepared patches was used for the assessment of drug release rates. For Peppas model, the results were illustrated depending on $\mathrm{n}$ values, when $(0.45<\mathrm{n}<0.89)$ means a non-Fickian diffusion and when $\mathrm{n}=0.45$ indicates Fickian diffusion (Higuchi model).

\section{RESULTS AND DISCUSSION}

\section{Drug excipient interaction study}

In DSC analysis, thermogram was obtained for pure drug showed a sharp endothermic peak at $198.23^{\circ} \mathrm{C}$, so the pure drug is semi-crystal, and the onset was $194.55^{\circ} \mathrm{C}$ as shown in Fig. 2.

The DSC analysis of the physical mixture of the drug with HPMC K15M and EC showed a broad peak at $59.41^{\circ} \mathrm{C}$ and $63.08^{\circ} \mathrm{C}$, respectively, as shown in Figs. 3 and 4 according to the adsorbed water on this polymers [17], with maintaining the sharp peak of the drug and no shifting in the onset melting point that means the drug and excipients were fused separately, and there was no physical interaction between the drug and excipients [10].

The DSC analysis of the physical mixture of the drug with Span 60, Tween 60 and Cremophor EL, showed a decrease in onset melting point around 8-15 with maintaining the sharp peak of the drug which indicated an interaction between the drug and the excipients, the results showed an interaction between the drug and this excipients Figs. 5-7.

\section{Physical appearance}

All patches showed transparence in color, smoothness, clarity and softness because of addition of the plasticizer which helped in the preparation of flexible matrix.

\section{Thickness uniformity}

The thickness of all patches was Up or equal to $0.1 \mathrm{~mm}$, results showed that thickness was increased with adding penetration enhancers.

\section{Folding endurance}

Folding endurance was measured, and the results were within a range of (18-10) as appears in Table 2 in which endurance increased with increasing the concentration of HPMC K15M. The ratio of HPMC K15M in the formula has affected the values of folding endurance since the formulas containing a greater percentage of the HPMC K15M were more strength and gave the greatest value for folding as in formula A1. Adding the penetration enhancers (Tween 60, Span 60, Cremophor EL) had reduced the strength of the matrix slightly and this is due to the oily appearance of these materials, which has contributed to the increased elasticity of the matrix. Backing membrane was measured alone which formed the backbone of the patch, and folding endurance was observed for 150 times.

\section{Percentage of moisture uptake and content}

The formulation FA2 showed a maximum of moisture uptake and content as seen in Tables 3 and 4, because of the effect of hydrophilic polymer HPMC K15M. The study indicated that there was a proportional relationship between the concentration of hydrophilic polymer and the moisture uptake and content of patches.

\section{Content uniformity}

All formulations confirmed uniformity of content. This result conforms to European Pharmacopeia requirements $(75-125 \%)$ as shown in Table 5.

Table 2: Folding endurance

\begin{tabular}{ll}
\hline Formula & Folding endurance \pm SD \\
\hline FA1 & $17 \pm 0.96$ \\
FA2 & $18 \pm 0.89$ \\
FA3 & $10 \pm 1.43$ \\
FB1 & $16 \pm 1.64$ \\
FB2 & $15 \pm 1.38$ \\
FB3 & $16 \pm 0.73$ \\
\hline
\end{tabular}

SD: Standard deviation

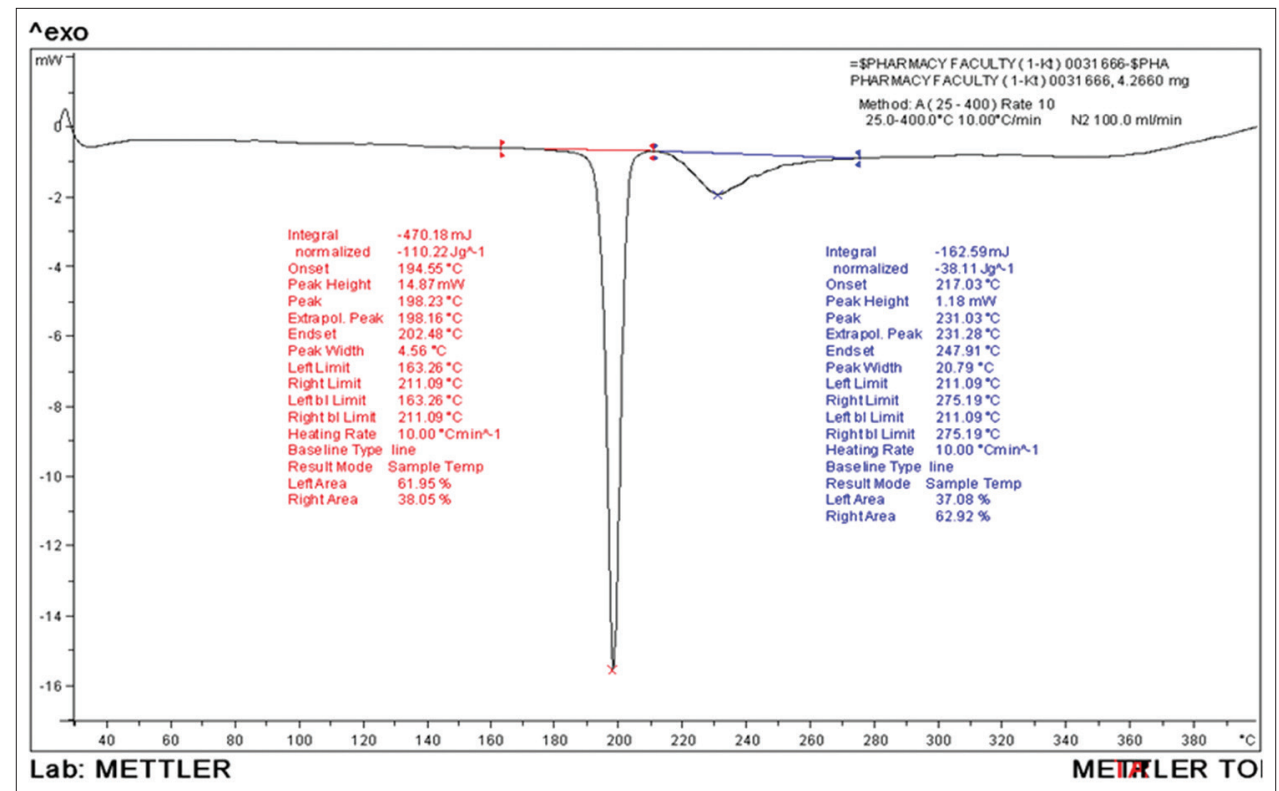

Fig. 2: Differential scanning calorimetry curve of pure Ketotifen fumarate 


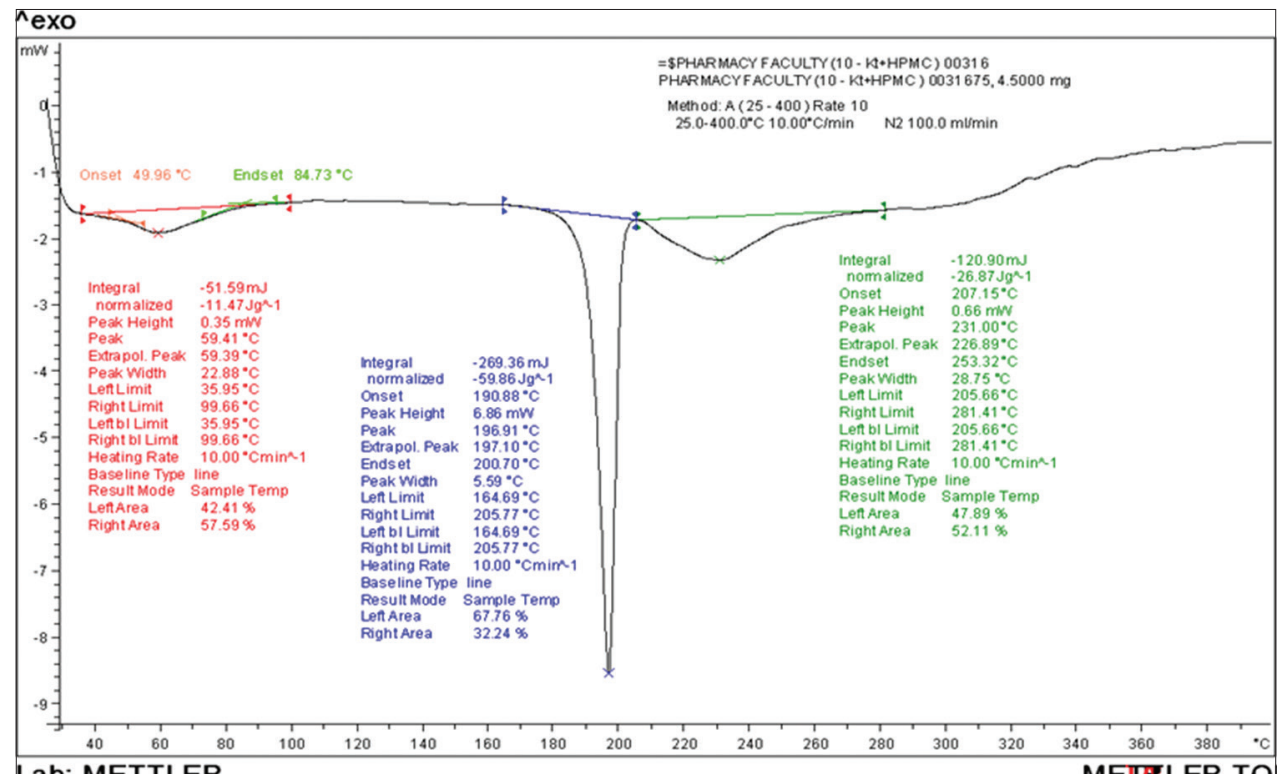

Fig. 3: Differential scanning calorimetry curve of physical mixture Ketotifen fumarate and hydroxypropyl methylcellulose K15M

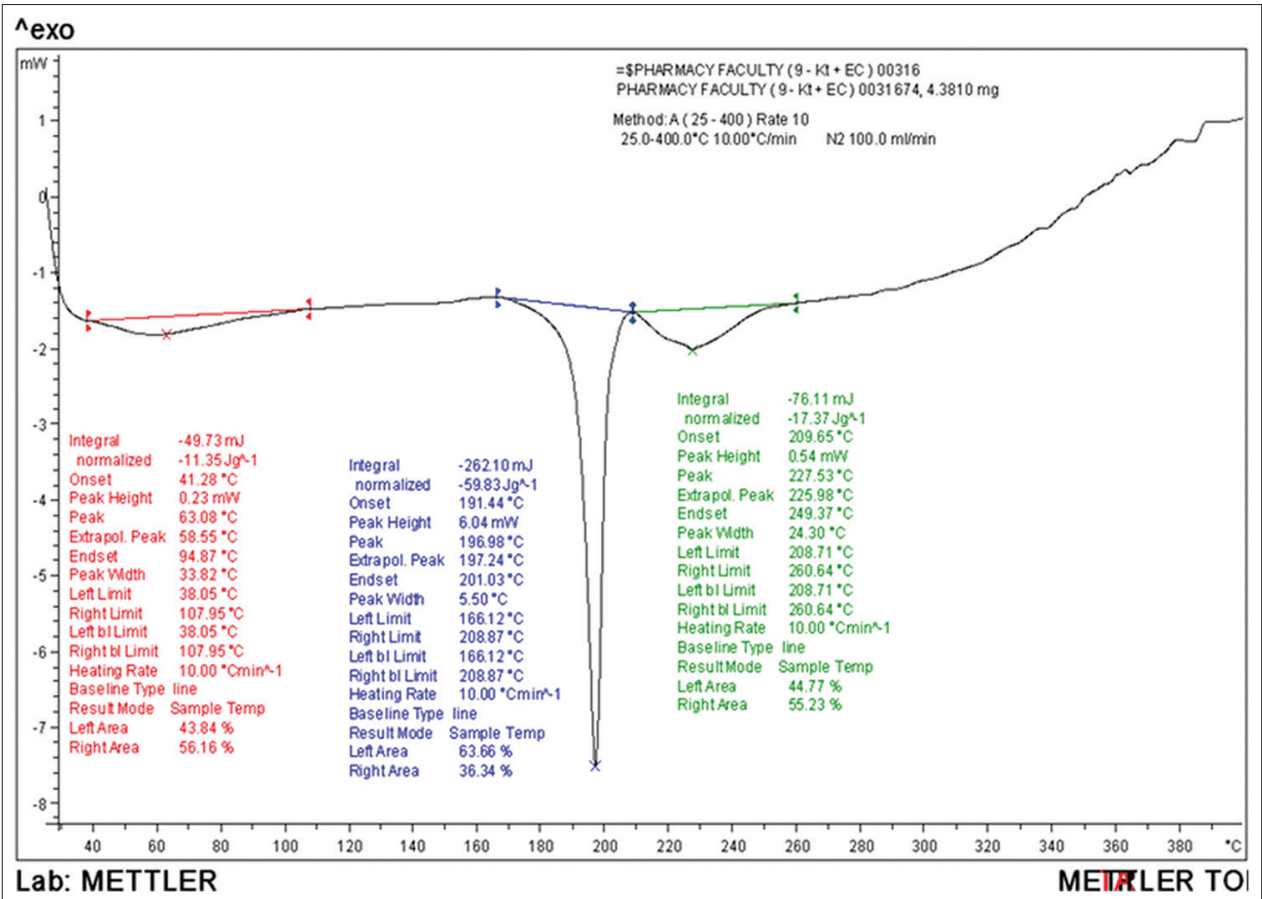

Fig. 4: Differential scanning calorimetry curve of physical mixture of Ketotifen fumarate and ethyl cellulose

Table 3: Moisture uptake

\begin{tabular}{llll}
\hline Formula & $\mathbf{2 4 H} \pm \mathbf{S D}$ & $\mathbf{4 8 H} \pm \mathbf{S D}$ & $\mathbf{7 2 H} \pm \mathbf{S D}$ \\
\hline FA1 & $0.90 \pm 0.13$ & $1.26 \pm 0.03$ & $1.39 \pm 0.21$ \\
FA2 & $1.03 \pm 0.68$ & $1.72 \pm 1.10$ & $1.40 \pm 1.43$ \\
FA3 & $0.17 \pm 0.13$ & $0.45 \pm 0.30$ & $0.89 \pm 0.66$ \\
FB1 & $0.98 \pm 0.08$ & $1.21 \pm 0.08$ & $1.36 \pm 0.08$ \\
FB2 & $1.08 \pm 0.47$ & $1.16 \pm 0.47$ & $1.35 \pm 0.36$ \\
FB3 & $0.75 \pm 0.51$ & $0.97 \pm 0.44$ & $1.01 \pm 0.47$ \\
\hline
\end{tabular}

SD: Standard deviation

In vitro release study

In vitro drug release after $24 \mathrm{hrs}$ was presented in Fig. 8. The formulation FA2 showed the maximum percentage of the drug release, due to the
Table 4: Moisture content

\begin{tabular}{llll}
\hline Formula & $\mathbf{2 4 H} \pm$ SD & $\mathbf{4 8 H} \pm$ SD & $\mathbf{7 2 H} \pm$ SD \\
\hline FA1 & $0.65 \pm 0.11$ & $0.71 \pm 0.07$ & $0.82 \pm 0.19$ \\
FA2 & $1.17 \pm 0.17$ & $1.17 \pm 0.49$ & $1.38 \pm 0.46$ \\
FA3 & $0.45 \pm 0.43$ & $0.78 \pm 0.23$ & $0.67 \pm 0.26$ \\
FB1 & $0.76 \pm 0.20$ & $1.37 \pm 0.15$ & $1.81 \pm 0.56$ \\
FB2 & $0.81 \pm 0.15$ & $1.39 \pm 0.04$ & $1.46 \pm 0.04$ \\
FB3 & $0.71 \pm 0.07$ & $1.26 \pm 0.11$ & $1.36 \pm 0.12$ \\
\hline
\end{tabular}

SD: Standard deviation

presence of hydrophilic polymer HPMC K15M which was swallowed and polymer chains opened when contacted with the dissolution medium and facilitated the drug release. 


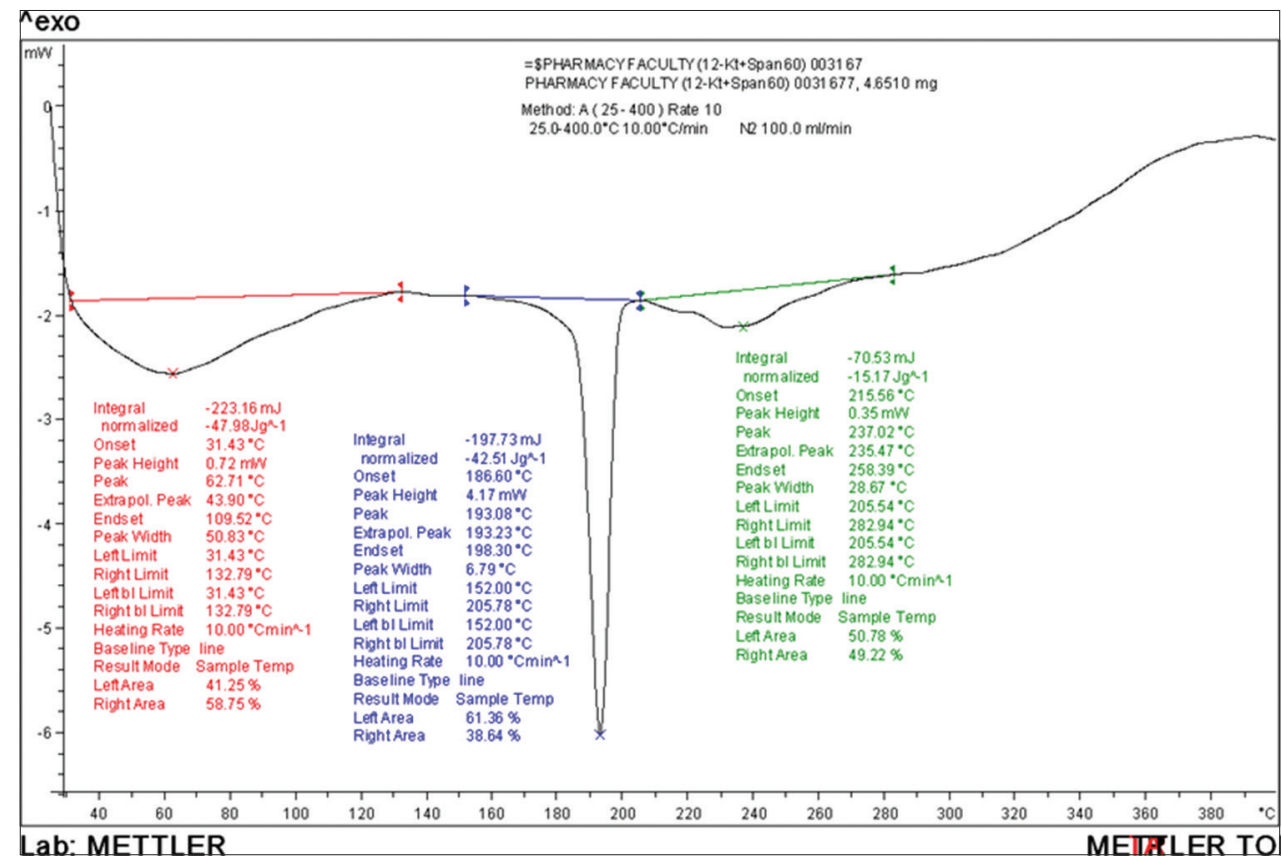

Fig. 5: Differential scanning calorimetry curve of physical mixture of Ketotifen fumarate and Span 60

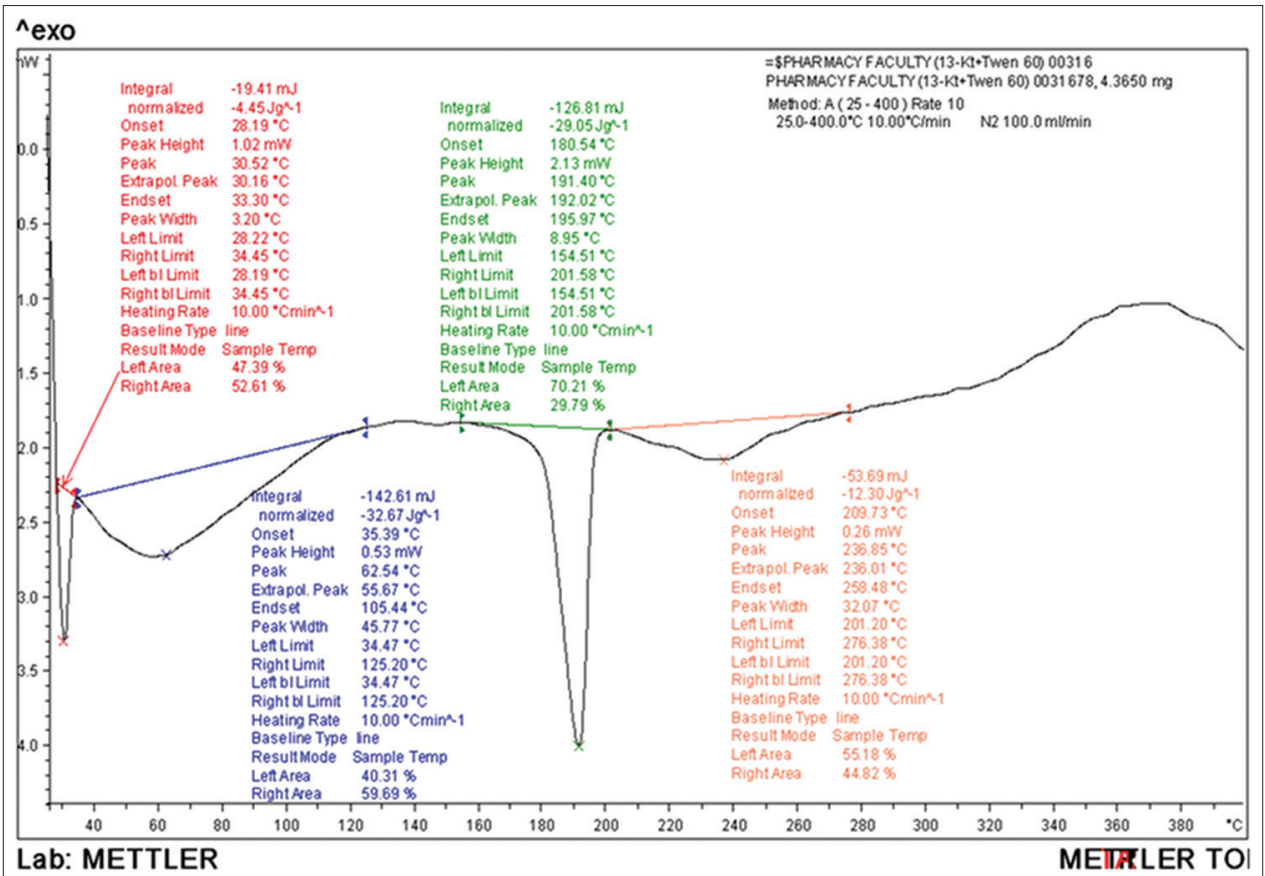

Fig. 6: Differential scanning calorimetry curve of physical mixture of Ketotifen fumarate and Tween 60

Table 5: Content uniformity

\begin{tabular}{ll}
\hline Formula & Content \pm SD \\
\hline FA1 & $99.44 \pm 1.14$ \\
FA2 & $95.74 \pm 0.91$ \\
FA3 & $94.04 \pm 1.06$ \\
FB1 & $96.94 \pm 1.25$ \\
FB2 & $95.89 \pm 0.90$ \\
FB3 & $94.64 \pm 0.99$ \\
\hline
\end{tabular}

SD: Standard deviation

The results showed the initial release of the drug after 15 minutes of the test in all formulations, and the formula FA2 was the fastest formula released by $6.17 \%$. The rapid release of the KT from the matrix that containing (HPMC K15M) may be due to the hydrophobic nature of the drug ( $\log \mathrm{p}=2.2)$, thus having a tendency to leave the matrix and reach the solubility medium. In addition, HPMC K15M has the ability to absorb water and be swallowed, which increases the speed of drug release.

The release rate of drug through the matrix decreased when the concentration of EC (hydrophobic polymer) was increased. However, adding different types of emulsifying agents had decreased the release rate of the drug Fig. 9, due to increasing the viscosity of the polymer HPMC K15M which kept the drug in the matrix and affected the released amount of the drug [18]. 


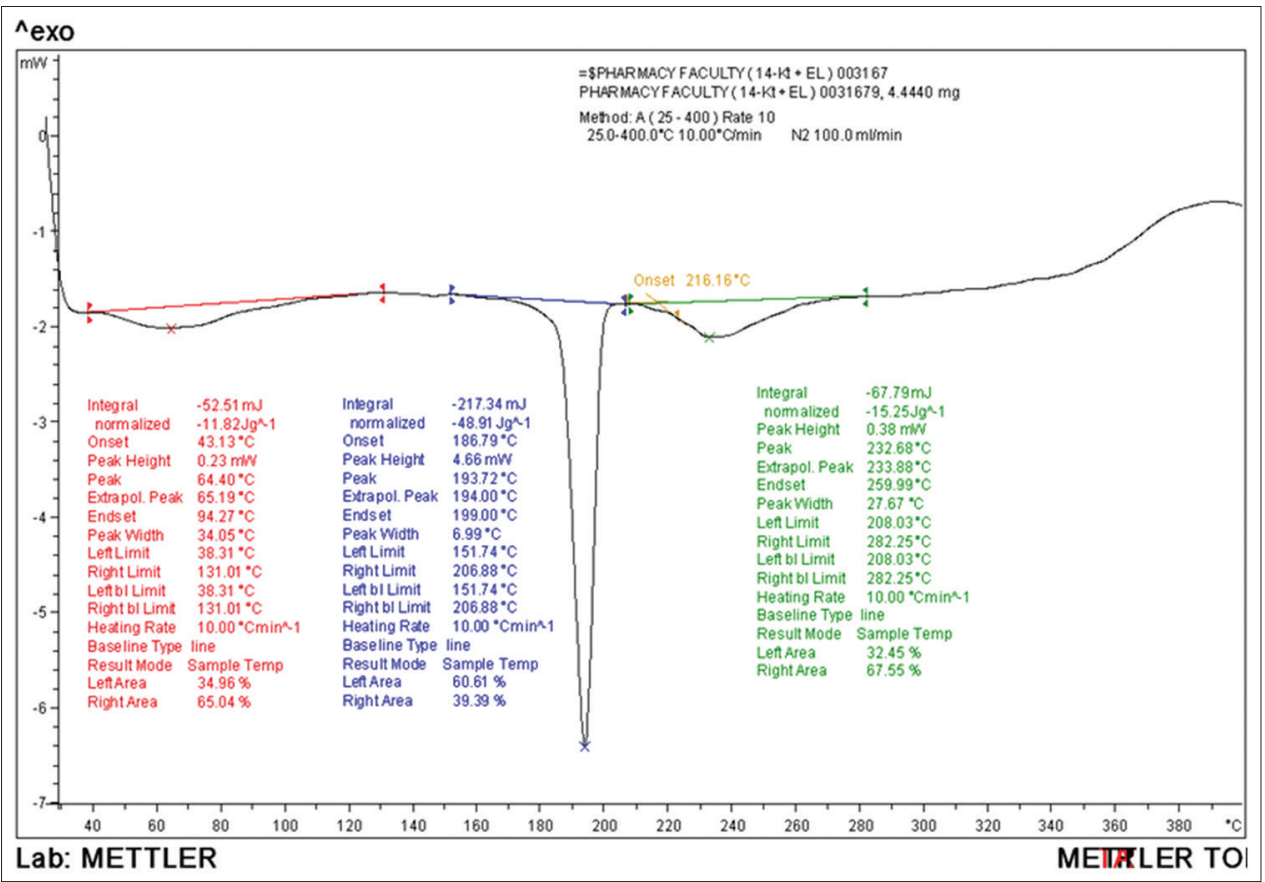

Fig. 7: Differential scanning calorimetry curve of physical mixture of Ketotifen fumarate and Cremophor EL

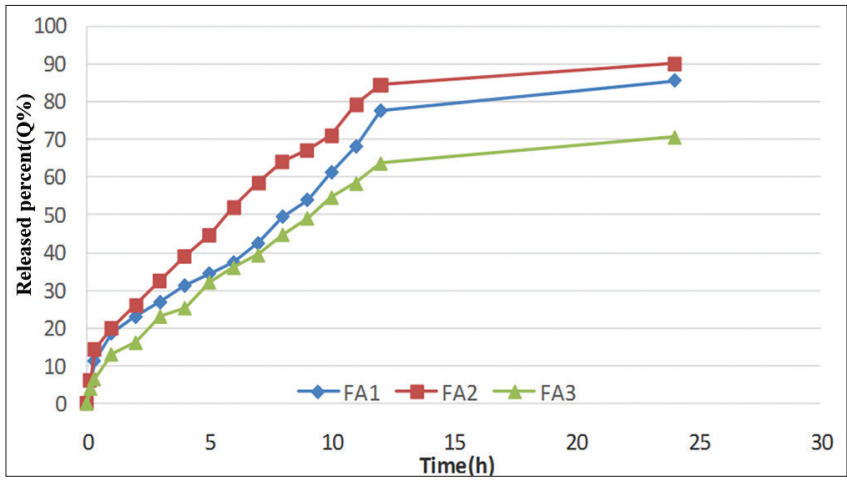

Fig. 8: Release of Ketotifen fumarate from various ratio of matrix

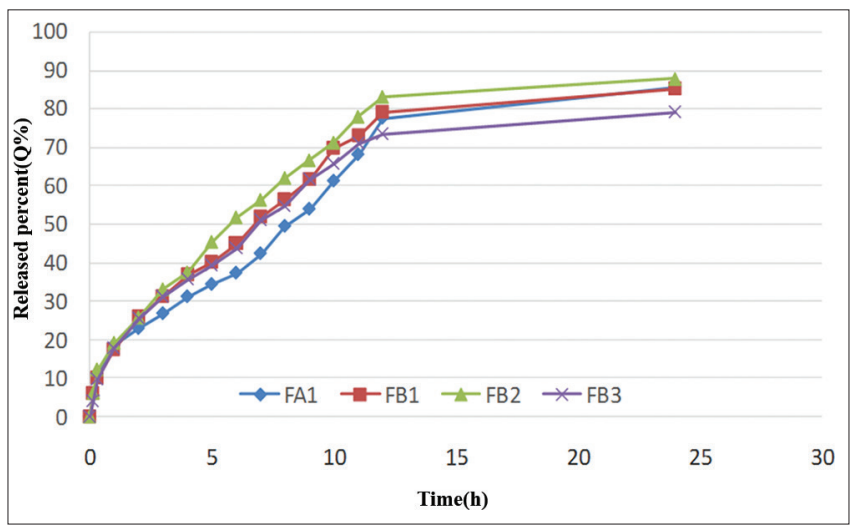

Fig. 9: Release of Ketotifen fumarate from matrix with penetration enhancer

The incomplete release of the drug may be due to the limited access of many drug molecules to the dissolution medium because of similar nature lipid properties of the excipients and the drug, which inhibited the release of the drug.
Tween 60 released the drug more than Span 60 because of ethylene oxide groups which linked with hydrogen bond acceptor in HPMC K15M that supported the release. Cremophor EL showed a minimum release because of formed micelles around the matrix which prevented the release of the drug.

\section{Statistical analyses of the outcomes}

Statistical analyses produced statistically significant differences among all formulations and $\mathrm{p}<0.05$. In fact, $\mathrm{p}$ values were halfway between 0.01 and 0.05 .

\section{Kinetic analysis of the release data}

In vitro release data of all formulations were in accord with different equations and kinetic to explain the release kinetics of the drug from transdermal patches, zero-order, first-order, Hixson-Crowell, Higuchi, and Korsmeyer-Peppas Models. The best fit with the highest coefficient of determination $\mathrm{r}^{2}$ was shown by Korsmeyer-Peppas model for all formulations. The release exponent (n) value was $<1$, confirming the release pattern was approaching zero-order Table 6.

\section{CONCLUSION}

Six formulations of KT patches were prepared using various ratios of polymers (HPMC K15M and EC). The formula A2 showed a maximum release $(90.06 \pm 0.9) \%$ for $24 \mathrm{hrs}$. Incorporation of emulsifying agents as penetration enhancers were decreased the release of the drug, the formula B2 that contained Tween 60 showed a maximum release of all the penetration enhancers $(87.78 \pm 0.88) \%$ and formula B3 having Cremophor EL showed minimum release of the drug $(79.13 \pm 1.58) \%$ at the end of 24 hrs dissolution study.

Physiochemical properties of patches. Kinetic release of the drug showed that all formulations released by Korsmeyer-Peppas model. The results were congruent with goals of the study and suggested that new controlled release transdermal formulations of antiasthmatic drugs can be used as an alternate to conventional dosage forms.

\section{ACKNOWLEDGMENT}

We gratefully acknowledge the team of Damascus University for medical science for the scientific collaboration of this paper. 
Table 6: Kinetic release data of formulation

\begin{tabular}{lllllll}
\hline Formula & Zero-order $\left(\mathbf{r}^{2}\right)$ & First-order $\left(\mathbf{r}^{2}\right)$ & Higuchi $\left(\mathbf{r}^{2}\right)$ & Hixon $\left(\mathbf{r}^{2}\right)$ & Peppas $(\mathbf{n})$ & Peppas $\left(\mathbf{r}^{2}\right)$ \\
\hline FA1 & 0.869 & 0.653 & 0.943 & 0.922 & 0.526 & 0.970 \\
FA2 & 0.802 & 0.595 & 0.948 & 0.895 & 0.528 & 0.972 \\
FA3 & 0.838 & 0.616 & 0.955 & 0.889 & 0.602 & 0.988 \\
FB1 & 0.815 & 0.607 & 0.952 & 0.890 & 0.544 & 0.989 \\
FB2 & 0.793 & 0.591 & 0.942 & 0.878 & 0.540 & 0.982 \\
FB3 & 0.787 & 0.544 & 0.947 & 0.856 & 0.585 & 0.976 \\
\hline
\end{tabular}

$\mathrm{r}^{2}$ : Correlation coefficient

\section{REFERENCES}

1. Incidence R, Allergic OF. Review articles advances in immunology. N J Med 2001;344(1):30-7.

2. Elbehairy DM, Osman R, Sammour O. Inhaled taste masked spray dried ketotifen microparticles formulation, characterization and in vitro pulmonary deposition. Int J Pharm Pharm Sci 2016;8(6):166-74.

3. El-kommos ME, El-gizawy SM, Atia NN, Hosny NM. Analysis for commonly prescribed non-sedating antihistamines. Anal Chem Res 2015;3:1-12.

4. Cannon J, RanadeV. Transdermal drug delivery. In: Drug Delivery System. $3^{\text {rd }}$ ed. Boca Raton: CRC Press; 2011. p. 243, 304.

5. Taylor K, editor. Topical and transdermal drug delivery. Aulton's Pharmaceutics: The Design and Manufacture of Medicines. $4^{\text {th }}$ ed. Edinburgh: Churchill Livingston; 2013. p. 676-97.

6. Kandavilli S, Nair V, Panchagnula R. Polymers in transdermal. Pharm Technol 2002;1195-206.

7. Allen VL, Nicholas G, Howard C. Transdermal drug delivery system. In: Ansel's Pharmaceutical Dosage Forms and Drug Delivery Systems. $10^{\text {th }}$ ed. USA: Lippincott William \& Wilkins; 2011. p. 342-62.

8. Yousuf M, Ahmad M, Usman M, Ali I. Ketotifen fumarate and salbutamol sulphate combined transdermal patch formulations: In vitro release and ex vivo permeation studies. Indian J Pharm Sci 2013;75:569-77.

9. Patel NA, Patel NJ, Patel RP. Design and evaluation of transdermal drug delivery system for curcumin as an anti-inflammatory drug. Drug Dev Ind Pharm 2009;35(2):234-42.

10. Park JB, Kang CY, Kang WS, Choi HG, Han HK, Lee BJ. New investigation of distribution imaging and content uniformity of very low dose drugs using hot-melt extrusion method. Int J Pharm 2013;458(2):245-53.

11. Khushbu K, Kumar SA, Kant SG, Swaraj P. Transdermal drug delivery of salbutamol sulphate with different. Concentration of polymers. Int J Res Pharm Sci 2011;1(3):50-65.

12. Kshirsagar SJ, Bhalekar MR, Mohapatra SK. Development and evaluation of carvedilol-loaded transdermal drug delivery system: In-vitro and in-vivo characterization study. Drug Dev Ind Pharm 2012;38:1530-7.

13. Mittal A, Sara US, Ali A, Mohammed A. Design, development, physicochemical, in vitro and in vivo evaluation of monolithic matrix type transdermal patches containing nitrendipine. Pharm Dev Technol 2009;14:422-34

14. Ravichandiran V, Manivannan S. Innovare academic sciences,wound healing potential of transdermal patches containg bioactive fraction from the bark of ficus pacemosa. Int J Pharm Pharm Sci 2015;7(6):326-32.

15. Fat H. In: Beck DC, editor. European Pharmacopeia. $7^{\text {th }}$ ed. Germany: WHO; 2011. p. 234

16. Sayeed MA, Farhad FM, Tareq SM, Islam N, Siddique SA, Das D. A study of in-vitro interaction of ketotifen fumarate with domperidone at different gastric and intestinal pH. Russ Open Med J 2014;3(2):5.

17. Clas S, Dalton CR, Hancock BC, Dalton CR, Hancock BC. Differential scanning calorimetry: Applications in drug development. Pharm Sci Technol Today 1999;2:1-8

18. Karakatsani M, Dedhiya M, Plakogiannis FM. The effect of permeation enhancers on the viscosity and the release profile of transdermal hydroxypropyl methylcellulose gel formulations containing diltiazem HCl. Drug Dev Ind Pharm 2010;36:1195-206. 